\title{
Chemical Characterization and Thermal Stressing Studies of Perfluorohexane Fluids for Space-Based Applications
}

\author{
William A. Arnold, Ph.D. ${ }^{1}$ \\ ZIN Technologies, Inc., Brook Park, Ohio, 44142, USA \\ Thomas G. Hartman, Ph.D. ${ }^{2}$ \\ CAFT, Cook College, Rutgers the Sate University of New Jersey, New Brunswick, NJ, 08901 USA \\ John McQuillen, ${ }^{3}$ \\ NASA Glenn Research Center, Cleveland, Ohio, 44135, USA
}

\begin{abstract}
Perfluorohexane (PFH), $\mathrm{C}_{6} \mathrm{~F}_{14}$, is a perfluorocarbon fluid. Several PFH fluids with different isomer concentrations were evaluated for use in an upcoming NASA space experiment. Samples tested included two commercially obtained high-purity n-perfluorohexane (n-PFH) fluids and a technical grade mixture of $\mathrm{C}_{6} \mathrm{~F}_{14}$ branched and linear isomers (FC-72 ${ }^{T M}$ ). These fluids were evaluated for exact chemical composition, impurity purity and high temperature degradation behavior (pyrolysis). Our investigation involved simulated thermal stressing studies of PFH fluids under conditions likely to occur in the event of an atmospheric breach within the International Space Station (ISS) and subsequent exposure of the vapors to the high temperature and catalyst present in its Trace Contaminant Control Subsystem (TCCS). Exposure to temperatures in the temperature range of $200-450^{\circ} \mathrm{C}$ in an inert or oxidizing atmosphere, with and without the presence of catalyst was investigated. The most aggressive conditions studied were exposure of $\mathrm{PFH}$ vapors to $450^{\circ} \mathrm{C}$ in air and in the presence of TCCS (palladium) catalyst. Gas chromatography-mass spectrometry (GC-MS) and gas chromatography (GC) analyses were conducted on the perfluorohexane samples before and after pyrolysis. The FC-72 and n-PFH samples showed no significant degradation following pyrolysis even under the most aggressive study conditions. Some trace level impurities associated with the PFH samples such as linear perfluorocarbon monohydrides or monoiodides were destroyed by pyrolysis at the upper limit. Other trace level impurities such as olefinic or cycloolefinic perfluorocarbons were converted into oxidation products by pyrolysis. The purity of PFH following pyrolysis actually increased slightly as a consequence since these trace contaminants were effectively scrubbed from the samples. However, since the initial concentrations of the thermally-impacted impurities were so low, the net effect was trivial. A potential byproduct of exposure of perfluorohexane fluids to high temperatures is the production of perfluoroisobutene (PFiB), which is extremely toxic. An ultra-high sensitivity PFiB-specific analysis based on GC-MS with negative ion chemical ionization (NICI) detection was used to evaluate the samples following thermal stressing. The perfluorohexanes examined here under conditions reflective of the ISS TCCS environment showed no signs of PFiB production with an analytical detection limit of 10 part per billion (ppb v/v).
\end{abstract}

\section{Nomenclature}

$\begin{array}{ll}B X F & =\text { Boiling eXperiment Facility } \\ E C L S S & =\text { Environmental Control and Life Support System } \\ E I & =\text { Electron Ionization } \\ F D A & =\text { Food and Drug Administration } \\ G C & =\text { Gas Chromatography } \\ H V A C & =\text { Heating, Ventilation and Air Conditioning } \\ I S R U & =\text { In-situ resource utilization }\end{array}$

\footnotetext{
${ }^{1}$ Interdisciplinary Engineer / Scientist, 2001 Aerospace Parkway, Brook Park, Ohio 44142.

${ }^{2}$ Mass Spectrometry Lab Manager \& Research Professor, CAFT, Rutgers the State University of New Jersey, 63 Dudley Road, New Brunswick, NJ 08901.

${ }^{3}$ Aerospace Engineer, 21000 Brookpark Rd., Cleveland, Ohio 44135.
} 


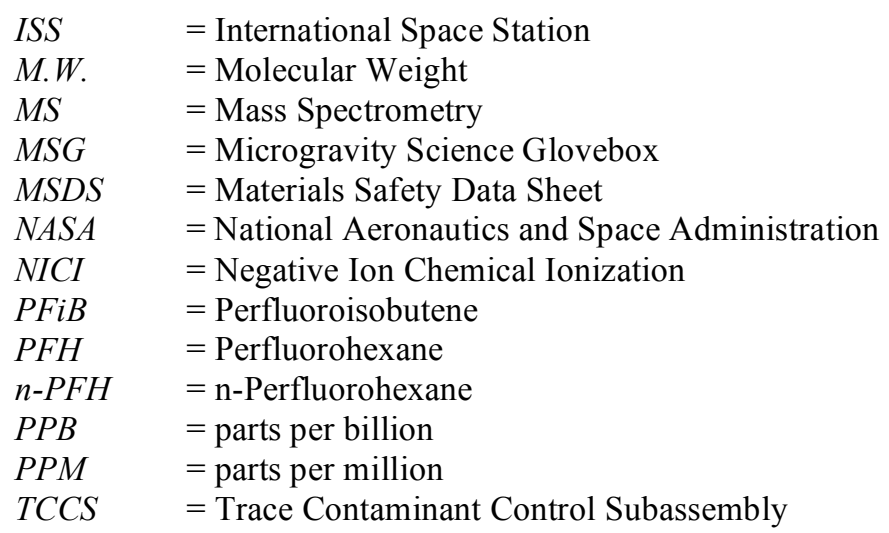

\section{Introduction}

The National Aeronautics and Space Administration (NASA) is currently developing several space experiments which use fluorocarbon fluids. These experiments are scheduled to be flown in the next few years. One such experiment is the Boiling eXperiment Facility (BXF) which uses a perfluorocarbon fluid called perfluorohexane (PFH). BXF provides a research platform to carry out critical research necessary for NASA's long term space objectives. This experiment will be carried out in the Microgravity Science Glovebox (MSG) aboard the International Space Station (ISS).

Boiling is known to be an efficient mode of heat transfer, and as such, it is employed in component cooling and in various energy conversion systems. Boiling is a complex phenomenon where the hydrodynamics, heat transfer, mass transfer, and interfacial phenomena are tightly interwoven. For space-based applications, boiling is the heat transfer mode of choice, since for a given power rating, the size of the components can be significantly reduced. For any space mission, the size and, in turn, the weight of the components plays an important role in the economics of the mission. Applications of boiling heat transfer in space can be found in the areas of thermal management, fluid handling and control, and power systems. It is of importance to space-based hardware and processes due to the large amounts of heat that can be removed with relatively little change in temperature. Design and development of safe operating procedures for on-orbit storage and supply systems for cryogenic propellants and life support fluids requires quantitative data for boiling heat transfer under long duration of microgravity conditions. An understanding of boiling and critical heat flux in microgravity environments is important to the design of future heat removal equipment for these space-based applications. 
A key element of the future space vehicles supporting the President's Vision for Space Exploration is the use of cryogenic liquids for the propulsion, power, and life support systems. Liquid hydrogen and liquid oxygen are the baseline propellants for the reusable launch vehicle main propulsion system. The proposed non-toxic upgrade of the space shuttle on-board propulsion systems uses liquid oxygen as a propellant. In-situ resource utilization (ISRU) has been shown to reduce, significantly, the earth launch mass of lunar and Mars missions. Central to the ISRU theme is the production, liquefaction and storage of oxygen and methane as propellants, oxygen as a reactant for localized power generation, and for crew life support. These systems can be expected to operate under gravity levels varying from $1 \mathrm{~g}$ to $10^{-6} \mathrm{~g}$, thus necessitating an understanding of boiling heat transfer including maximum and minimum heat fluxes at these gravity levels.

At present, there is little understanding of this important mode of heat transfer at low gravity levels, and consequently, there are no verified correlations or models that a designer can use to design efficient heat exchange equipment with any level of confidence. Although much research in this area has been performed since the Space Station was proposed, the mechanisms by which heat is removed from surfaces under these environments are still unclear. The BXF will go a long way in providing a sound physical basis for the development of design guidelines.

Of special importance with relevance to the fluid analyses presented in this paper is the potential use of fluorocarbon fluids in heat transfer loops in space-based operations. The use of these fluorocarbon fluids as heat transfer fluids could potentially reduce current two-loop systems, which use two different fluids and heat exchangers, to one loop system using one fluid. In addition, a single fluid system would not require heat exchangers to thermally couple two different fluids.

Waste heat needs to be transported from its source to a sink in order to ensure continued operation of machinery and electronics. For spacecraft, this heat is rejected to ambient environment either through radiation heat transfer or through the evaporation or sublimation of a volatile fluid. Transporting the heat internal to the spacecraft relies on conduction and often fluid convection through ducted channels. The acquisition, transport and rejection of heat is classified as "thermal management."

Fluid selection for thermal management systems requiring convective heat transport is based on multiple criteria:

- The heat source or acquisition temperature affects whether the thermal fluid is vapor or liquid based on the fluid's boiling point

- The heat sink or rejection temperature compared to the fluid's freezing point. 
- The fluid's thermal properties, such as heat capacity and latent heat of vaporization, set the fluid's heat carrying capabilities.

- The fluid's hydrodynamic properties, such as viscosity and density, which determines the amount of power required to pump the fluid at the necessary flow rates.

- The fluid's corrosive properties, especially with regards to materials such as metals that are used in heat transfer applications.

- The fluid's toxicity and flammability especially in the event of a leak, but also with regards to filling and draining operations.

Early manned spacecraft, such as Apollo, accepted the risk associated with fluid toxicity by utilizing an ethylene glycol mixture as the thermal management fluid. This system was a "single-phase" system. To account for periods of low heat rejection, some fluid in the parallel radiator legs was allowed to freeze ${ }^{1}$.

Recent spacecraft, namely the ISS and the space shuttle ${ }^{2}$, utilize a dual-loop configuration. An internal flow loop circulates a "non-toxic" single-phase fluid, water, through the crewed portions of the vehicle and then transfers heat to an external loop that circulates another, usually toxic, fluid to the radiator. The external flow loop for the ISS uses liquid ammonia and for the space shuttle uses liquid R-21 (fluorodichloromethane).

For closed loop life support systems, those that filter and scrub the air for particulate matter, harmful contaminants and carbon dioxide, the toxicity of both the fluid and its high temperature decomposition products need to be accounted for. The Environmental Control and Life Support System (ECLSS) for the ISS has a Trace Contaminant Control Subassembly (TCCS) that is used to absorb or decompose trace amounts of contaminants in the cabin atmosphere that could otherwise gradually build up over time to toxic levels. The TCCS consists of an activated carbon bed that absorbs the longer chain carbon molecules, a catalytic converter to thermally decompose contaminants, and a lithium hydroxide bed to neutralize the acidic byproducts of the decomposition reaction ${ }^{3}$. The thermal decomposition reaction occurs at temperatures of $450^{\circ} \mathrm{C}$.

Fluorocarbon compounds have been identified as an acceptable alternative working fluid for Heating, Ventilation and Air Conditioning (HVAC) systems and also for electronic cooling. These fluids are relatively inert within these systems, i.e., they do not corrode the metals used in these systems, and they are "friendly" to the atmospheric ozone layer. NASA has identified that some of these fluorocarbon fluids may be suitable thermal 
management heat transfer fluids in terms of utilization within the space environment, primarily because of their low freezing point.

Perfluorohexane, $\mathrm{C}_{6} \mathrm{~F}_{14}$, is a highly inert fluorocarbon that actually describes several different isomers. These isomers are shown in Figure 1. The Materials Safety Data Sheet (MSDS) ${ }^{4}$ for FC-72 ${ }^{\mathrm{Tm}}$, a trademarked $3 \mathrm{M}$ heat transfer fluid consisting of several PFH isomers, indicates that the chemical compound is fairly inert and even benign in most cases. It is one of a group of candidate fluids for replacement blood because of its affinity for oxygen (absorbs roughly 50 volume percent of its liquid volume), its use has no risk of transmission of pathogenic microorganisms, and it is not metabolized within the body ${ }^{5}$. PFH is also currently registered for use by the US Food and Drug Administration (FDA) in an intravenously-administered formulation (Imagent ${ }^{\mathrm{TM}}$ ) used as contrast agent in cardiac ultrasound imaging. The injected dose in humans is non-metabolized and is completely excreted from the breath within 24 hours. Despite the inertness and extreme low toxicity of PFH, there are concerns of toxicity associated with potential thermal decomposition or pyrolysis products. For instance, the MSDS for PFH states that exposure to temperatures in excess of $200^{\circ} \mathrm{C}$ could result in the decomposition of FC-72 into hydrogen fluoride and perfluoroisobutene (PFiB). 


$$
\mathrm{CF}_{3}-\mathrm{CF}_{2}-\mathrm{CF}_{2}-\mathrm{CF}_{2}-\mathrm{CF}_{2}-\mathrm{CF}_{3}
$$

n-perfluorohexane

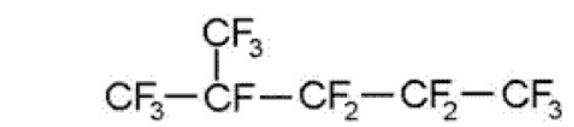

2-methylperfluoropentane or iso-perfluorohexane

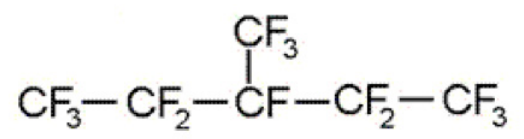

3-methylperfluoropentane

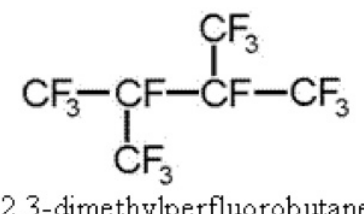

2,3-dimethylperfluorobutane

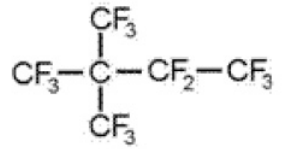

2,2-dimethylperfluorobutane

\section{Fig. 1 Several different $C_{6} F_{14}$ perfluorohexane isomers.}

PFiB was initially identified as the cause of "Teflon flu" which is a highly fatal illness attributable to inhalation of Teflon decomposition products ${ }^{6}$ and has an acceptable exposure limit of 10 parts per billion ${ }^{7}$. Subsequent studies on PFiB have shown severe pulmonary injuries from short exposures to "high" concentrations that may go undetected immediately after the exposure. ${ }^{8}$ More recent tests have shown that although PFiB is still regarded as highly toxic, ultrafine particles that are generated during the combustion or pyrolysis of Teflon are now accepted as the principle lethal agent ${ }^{9,10,11}$.

Dependent on the presence of other chemical species, perfluorocarbons can decompose into hydrogen fluoride (HF), carbonyl fluoride $\left(\mathrm{COF}_{2}\right)$, carbon monoxide $(\mathrm{CO})$, carbon dioxide $\left(\mathrm{CO}_{2}\right)$, and perfluoro-iso-butylene $\left(\left(\mathrm{CF}_{3}\right)_{2} \mathrm{CCF}_{2}\right)$.

Because of the high-temperature catalytic reactor that is used in most air revitalization systems, not only the ISS TCCS, it is necessary to assess whether perfluorocarbons that are volatilized into an air stream will decompose into toxic substances such as PFiB. 
The PFiB formation mechanism is commonly postulated as a series of additive reactions involving the highly reactive fluorocarbene free radical, CF2, with short chain perfluoroalkanes and perfluoropropene. Hauptschein, et al. ${ }^{12}$, attempted thermal dimerization of perfluoropropene under both short duration "flow" conditions and long duration "stagnant" conditions. Perfluoropropene $\left(\mathrm{CF}_{2}\right)_{3}$ is a cycloalkane. In the first case, they found that for contact times of about 10 seconds in a hot tube of $510^{\circ} \mathrm{C}$ at atmospheric pressure, there was no reaction. However, after seven hours of exposure to the same conditions in a sealed, a six percent conversion was noted. PFIB was not detected in reactions below $700{ }^{\circ} \mathrm{C}$. Salmon, et al. ${ }^{13}$ conducted experiments of chlorodifluoromethane, 1,1,1,2tetrafluoro-2-chloroethane, trifluoromethane, and perfluoropropene in nitrogen at temperatures of 550 to $1000{ }^{\circ} \mathrm{C}$ with exposure times of two seconds at atmospheric pressure. While they were able to obtain significant conversion of PFiB based upon the carbon content of the feed material, they did not detect any PFiB below reactor temperatures

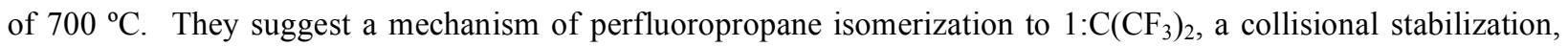
and the eventual addition of the fluorocarbene radical.

Tortelli, et $\mathrm{al}^{14}$, attributed the thermal stability upon the extent of branching and bulkiness (chemical-bond steric constraint) of the molecules. One disturbing reaction was the pyrolysis of 2,3,3-trifluoromethylperfluoropentane that generates PFiB. The branching similarity in the structure of 2,3,3-trifluoromethylperfluoropentane to 2,2dimethylperfluorobutane suggests that PFiB could be a potential decomposition product for some perfluorohexane isomers. Later, Tonelli and Tortelli ${ }^{15}$ identified conditions favorable for the formation of PFiB included the presence of a hot surface in a perfluorocarbon-rich environment which can be accelerated by the presence of halogen gasses such as chlorine or bromine gas. However, it should be noted, that in both of these studies, the perfluorocarbon was sealed within a tube, either by itself or with the other reactant (the chlorine or bromine gas) and allowed to react for a period of at least an hour at the high temperature.

Ainogas ${ }^{16}$ specifically examined the pyrolysis of normal perfluorohexane at temperatures exceeding $700^{\circ} \mathrm{C}$ in a helium at atmospheric pressure. While the isomer did decompose, there was no indication that PFiB was formed.

In order to assess the thermal decomposition of perfluorohexane vapor that is applicable to removing trace contaminants in a closed loop life support system, two other factors need to be considered: the presence of air, specifically oxygen, and the residence time or the time that the perfluorocarbon is in contact with the hot surface of the catalytic bed. 
While data is lacking for perfluorohexane isomers under these conditions, there are data available on behaviors for perfluoroalkanes with five carbons or less and for polymer chains that have many carbon chains present. Arito and Soda ${ }^{17}$ investigated the high temperature decomposition products of polytetrafluoroethylene (PFTE) in both dry and wet air streams, and found that the formation of PFiB occurred in a nitrogen stream and that the formation in PFTE was suppressed by the presence of oxygen. No mechanism was proposed.

Trowbridge ${ }^{18}$ conducted a literature survey of the decomposition of perfluorocyclobutane, perfluoroethylene and other polymeric perfluorocarbons such as PTFE. The presence of oxygen suppressed the formation of PFiB, but also led to the formation of other toxic compounds such as $\mathrm{HF}$ (hydrogen fluoride), $\mathrm{CO}$ (carbon monoxide), $\mathrm{COF}_{2}$ (carbonyl fluoride), $\mathrm{CF}_{4}$ (methane) and $\mathrm{CO}_{2}$ (carbon dioxide). He did cite some sources that did indicate PFIB formation under conditions that at least initially contained oxygen. These involved the pyrolysis of solid fluorocarbon polymers, such as PTFE, which are high density sources of reactant (versus gas-phase oxygen) that possibly depleted the available oxygen before the PFiB was generated.

Trowbridge ${ }^{19}$ later conducted an analysis of the reaction kinetics for additional 4-carbon compounds, namely c$\mathrm{C}_{4} \mathrm{~F}_{8} \mathrm{O}$, n- $\mathrm{C}_{4} \mathrm{~F}_{10}$ (normal- perfluorobutane)and $\mathrm{c}-\mathrm{C}_{4} \mathrm{~F}_{8}$ (cycloperfluorobutane) and confirmed the previous literature survey and analysis.

With regards to the residence time, there have been several studies also on this topic. Hauptschein, et al., in their study found that for short duration, "flow-like" exposure conditions, perfluoropropene exposure to high temperature resulted in no decomposition, but batch reactions did. Decorpo, et. $\mathrm{al}^{20}$ conducted tests on Teflon packing around a rotating shaft. They found no PFiB was generated when the packing reached about $480{ }^{\circ} \mathrm{C}$ for 30 seconds. They asserted that both the failure of air circulation and long duration exposure of the Teflon to the high temperatures were required before PFiB could be generated. The argument that the air circulation needed to be stopped before the PFiB was generated also involves the oxygen depletion argument associated with the solid perfluorocarbon compounds.

Our investigation involved simulated thermal stressing studies of PFH fluids under conditions likely to occur in the event of a breach in the BXF triple containment system within the ISS and subsequently expose the vapors to high temperature and catalyst present in the TCCS. The PFH fluids were analyzed before and after thermal stressing. The conditions of the thermal stressing studies such as transit time, atmospheric gas composition, pressure, temperature and catalyst exposure were modeled based on TCCS operational specifications. Please note, 
the terms "pyrolysis" and "thermal stressing" are used interchangeably in this report. However, the authors acknowledge the term thermal stressing more scientifically defines the experiments conducted. The term pyrolysis refers to rapid heating to high temperatures $\left(\sim 600-800^{\circ} \mathrm{C}\right)$ in the absence of oxygen so thermal dissociation of chemical bonds results rather than combustion. Our studies were conducted at sub-pyrolytic temperatures in the range of $200-450^{\circ} \mathrm{C}$ and some experiments were in the presence of oxygen (air) so the strict definition of the term pyrolysis was not met. Nonetheless, the term pyrolysis in this paper is used generically to describe the thermal stressing experiments.

\section{Fluid Purity and Composition Analyses}

\section{$\underline{\text { Fluid Samples }}$}

Perfluorohexane fluids were the focus of this investigation and were obtained from commercial sources. High purity reference standards consisting primarily of the linear isomer, n-perfluorohexane (PFH) were obtained from Aldrich Chemical Company (Lot \#18025DB) and F2 Chemicals LTD (Batch No. 0219C). A sample of mixed perfluorohexane isomers with the tradename $\mathrm{FC}-72^{\mathrm{тм}}$ was obtained from $3 \mathrm{M}$ Corporation. Detailed chemical composition analyses of these samples were performed using analysis conditions detailed in the next section.

\section{Analytical Methodology}

The PFH and FC-72 samples were analyzed for exact chemical composition and impurity profile by capillary gas chromatography - mass spectrometry (GC-MS) using both electron ionization (EI) and negative ion chemical ionization (NICI) modes of operation. The samples were also analyzed by gas chromatography with flame ionization detection (GC-FID). The GC-FID analyses were conducted to provide quantitative data on sample purity (GC Area \%) due to the increased dynamic range of the GC-FID technique. Chemical composition and identity of impurities were obtained from the GC-MS data. The GC-MS analyses were also designed to detect potential impurities such as HF that do not yield a signal in an FID detector. Cryogenic GC temperature programming was employed to provide optimum chromatographic resolution of test substances. Details of the GC-MS and GC-FID analyses are provided next. 
GC-MS analyses were performed on a Varian 3400 GC directly interfaced to a Finnigan MAT 8230, high resolution, double focussing, magnetic sector type mass spectrometer. Neat $0.1-1.0 \mu l$ injections of fluorocarbon fluids were made on a 60 meter x $0.25 \mathrm{~mm}$ I.D. SPB-1 (non-polar polydimethylsiloxane bonded phase) capillary column containing a $1.0 \mu \mathrm{m}$ film thickness. The injector temperature was $220^{\circ} \mathrm{C}$ and an injector split ratio of $200: 1$ was employed. The GC column was temperature programmed from $-30^{\circ}$ (hold $1.0 \mathrm{~min}$.) to $40^{\circ} \mathrm{C}$ at a rate of $4^{\circ} \mathrm{C}$ per minute (zero hold) then up to $260^{\circ} \mathrm{C}$ at a rate of $20^{\circ} \mathrm{C}$ per minute with a 10 minute hold at the upper limit. The GC column flow rate was $1.0 \mathrm{ml}$ per minute (26 psi head pressure) using helium carrier gas and the GC-MS transfer line temperature was $260^{\circ} \mathrm{C}$. MS data was recorded using both EI $(70 \mathrm{eV})$ and NICI modes of operation. In EI mode the mass spectrometer was scanned from $20-750 \mathrm{amu}$ at a rate of 0.6 seconds per decade with a 0.8 second interscan time for magnet reset. The NICI analyses were conducted using isobutane reagent gas at a source pressure of 0.7 Torr scanning masses 20-750 amu at a rate of 0.6 seconds per decade with a 0.8 second interscan time. The filament emission current and ionization source temperature for both the EI and NICI analyses were 0.5 milliamperes and $250^{\circ} \mathrm{C}$, respectively. In both EI and NICI analyses, the mass spectrometer resolution was 1000 and mass calibration was performed using perfluorokerosene (PFK). Data were recorded and processed using a Finnigan MAT SS300 data system and/or a Micromass MassLynx data system.

GC-FID analyses were performed on a Varian $3400 \mathrm{GC}$ using chromatographic run conditions identical to those described for GC-MS except the FID detector temperature was $280^{\circ} \mathrm{C}$ with a detector make up gas at $30 \mathrm{ml} / \mathrm{min}$. The GC-FID chromatograms were recorded and processed using an SRI PeakSimple data system.

The EI and NICI MS data were interpreted to provide absolute structure identification and/or structural characterization of perfluorocarbon fluid components. Structural assignments were based on comparison of EI spectra to the US National Institute of Standards \& Technology (NIST) database, by reference to an extensive perfluorocarbon mass spectral data base compiled by one of the authors, literature references, molecular weight confirmation afforded by the NICI data, manual interpretation of EI and NICI mass spectral fragmentation patterns and correlation with GC retention time index compiled from reference standards. One of the authors has been working with perfluorocarbons used in pharmaceuticals, medical diagnostics, anesthetics, industrial coatings, gases for semiconductor manufacture, textiles and other industrial applications for over 20 years and maintains an extensive unpublished mass spectral perfluorocarbon database, a GC retention time index and is skilled in 
interpretation of mass spectra of perfluorinated compounds and decomposition products. Quantitative data based on GC peak area percent was obtained from the GC-FID analyses assuming an FID response factor of 1.0 for all detected components.

$\underline{\text { Results \& Discussion for PFH and FC-72 Chemical Composition }}$

The chemical composition data from the GC-MS and GC-FID analyses of the FC-72, Aldrich PFH, and F2 Chemicals PFH samples are summarized in Tables $1,2 \& 3$ respectively. From left to right, the columns in each Table list the structural assignment, molecular weight (M.W.) and the percent composition based on GC peak area $\%$. The compounds are listed in order of elution from the GC (in order of increasing boiling point). Compounds listed as trace $(<0.001 \%)$ were detected in the GC-MS analyses but were below the threshold for reliable peak area integration in the GC-FID data. Compounds listed as ultra-trace $(<0.0001 \%)$ were impurities present at exceedingly trace concentration and were typically detected only in the NICI-GC-MS data.

The Aldrich and F2 Chemicals LTD PFH samples consist primarily of n-perfluorohexane $(99 \%+)$ along with trace impurities. The FC-72 fluid contains n-perfluorohexane as the major component (73.2\%), significant quantities of branched $\mathrm{C}_{6} \mathrm{~F}_{14}$ isomers and cyclic $\mathrm{C}_{6} \mathrm{~F}_{12}$ species along with other trace level impurities. The combined percentage of $\mathrm{C}_{6} \mathrm{~F}_{14}$ isomers in the $\mathrm{FC}-72$ fluid are approximately $98.8 \%$.

\begin{tabular}{|c|c|c|}
\hline \multicolumn{2}{|c|}{ Table 1 GC-MS/GC-FID Profile of FC-72 } & GC Area \% \\
\hline \hline Structural Assignment & M.W. & trace $(<0.001 \%)$ \\
\hline n-perfluorobutane & 238 & trace $(<0.001 \%)$ \\
\hline n-perfluoropentane & 288 & trace $(<0.001 \%)$ \\
\hline perfluoro-2-methylbutane (perfluoroisopentane) & 288 & trace $(<0.001 \%)$ \\
\hline $\mathrm{C}_{6} \mathrm{~F}_{14} \mathrm{O}$ isomer & 354 & 73.200 \\
\hline n-perfluorohexane & 338 & 17.892 \\
\hline perfluoro-2-methylpentane (perfluoroisohexane) & 338 & 5.954 \\
\hline perfluoro-3-methylpentane & 338 & 1.105 \\
\hline Perfluorocyclohexane & 300 & 1.723 \\
\hline perfluoro-2,3-dimethylbutane + perfluoro-2,2-dimethylbutane & 338 & \\
\hline
\end{tabular}




\begin{tabular}{|c|c|c|}
\hline perfluoromethylcyclopentane & 300 & 0.126 \\
\hline n-perfluoroheptane & 388 & $\operatorname{trace}(<0.001 \%)$ \\
\hline perfluoro-2-methylhexane (perfluoroisoheptane) & 388 & $\operatorname{trace}(<0.001 \%)$ \\
\hline $\mathrm{C}_{7} \mathrm{~F}_{14}$ isomer & 350 & ultra-trace $(<0.0001 \%)$ \\
\hline $\mathrm{C}_{7} \mathrm{~F}_{14}$ isomer & 350 & ultra-trace $(<0.0001 \%)$ \\
\hline $\mathrm{C}_{7} \mathrm{~F}_{14}$ isomer & 350 & ultra-trace $(<0.0001 \%)$ \\
\hline $\mathrm{C}_{7} \mathrm{~F}_{14}$ isomer & 350 & ultra-trace $(<0.0001 \%)$ \\
\hline $\mathrm{C}_{8} \mathrm{~F}_{16} \mathrm{O}$ isomer & 416 & $\operatorname{trace}(<0.001 \%)$ \\
\hline n-perfluorooctane & 438 & $\operatorname{trace}(<0.001 \%)$ \\
\hline perfluoro-2-methylheptane & 438 & $\operatorname{trace}(<0.001 \%)$ \\
\hline perfluoro-3-methylheptane & 438 & $\operatorname{trace}(<0.001 \%)$ \\
\hline $\mathrm{C}_{8} \mathrm{~F}_{16} \mathrm{O}$ isomer & 416 & ultra-trace $(<0.0001 \%)$ \\
\hline $\mathrm{C}_{8} \mathrm{~F}_{16} \mathrm{O}$ isomer & 416 & trace $(<0.001 \%)$ \\
\hline $\mathrm{C}_{8} \mathrm{~F}_{16} \mathrm{O}$ isomer & 416 & $\operatorname{trace}(<0.001 \%)$ \\
\hline $\mathrm{C}_{8} \mathrm{~F}_{16} \mathrm{O}$ isomer & 416 & ultra-trace $(<0.0001 \%)$ \\
\hline $\mathrm{C}_{8} \mathrm{~F}_{16}$ isomer & 400 & ultra-trace $(<0.0001 \%)$ \\
\hline $\mathrm{C}_{8} \mathrm{~F}_{16} \mathrm{O}$ isomer & 416 & ultra-trace $(<0.0001 \%)$ \\
\hline $\mathrm{C}_{8} \mathrm{~F}_{16}$ isomer & 400 & ultra-trace $(<0.0001 \%)$ \\
\hline
\end{tabular}

Table 2 GC-MS/GC-FID Profile of Aldrich Lot \#18025DB PFH

\begin{tabular}{|c|c|c|}
\hline \hline Peak Assignment & M.W. & GC Area \% \\
\hline $\mathrm{C}_{6} \mathrm{~F}_{14} \mathrm{O}$ isomer & 354 & trace $(<0.001 \%)$ \\
\hline n-perfluorohexane $(\mathrm{PFH})$ & 338 & 99.399 \\
\hline perfluorocyclohexane & 300 & trace $(<0.001 \%)$ \\
\hline $\mathrm{C}_{6} \mathrm{~F}_{12} \mathrm{O}$ isomer & 316 & ultra-trace $(<0.0001 \%)$ \\
\hline $\mathrm{C}_{6} \mathrm{~F}_{12} \mathrm{O}$ isomer & 316 & ultra-trace $(<0.0001 \%)$ \\
\hline perfluoromethylcyclopentane & 300 & 0.019 \\
\hline $\mathrm{C}_{7} \mathrm{~F}_{14}$ isomer, $(\mathrm{C} 7$ perfluorocarbon w/ one ring or double bond $)$ & 350 & ultra-trace $(<0.0001 \%)$ \\
\hline $\mathrm{C}_{7} \mathrm{~F}_{14}$ isomer, $(\mathrm{C} 7$ perfluorocarbon w/ one ring or double bond $)$ & 350 & ultra-trace $(<0.0001 \%)$ \\
\hline
\end{tabular}




\begin{tabular}{|c|c|c|}
\hline $\mathrm{C}_{6} \mathrm{~F}_{10}$ isomer, (C6 perfluorocarbon w/ two rings or double bonds) & 262 & ultra-trace $(<0.0001 \%)$ \\
\hline $\mathrm{C}_{6} \mathrm{~F}_{10}$ isomer, (C6 perfluorocarbon w/ two rings or double bonds) & 262 & 0.114 \\
\hline $\mathrm{C}_{7} \mathrm{~F}_{10}$ isomer, (C7 perfluorocarbon w/ three rings or double bonds) & 274 & ultra-trace $(<0.0001 \%)$ \\
\hline $\mathrm{C}_{7} \mathrm{~F}_{10}$ isomer, (C7 perfluorocarbon w/ three rings or double bonds) & 274 & ultra-trace $(<0.0001 \%)$ \\
\hline n-perfluorooctane & 438 & 0.021 \\
\hline n-perfluorohexyl-1-hydride & 320 & 0.047 \\
\hline $\mathrm{C}_{6} \mathrm{~F}_{10}$ isomer, (C6 perfluorocarbon w/ two rings or double bonds) & 262 & ultra-trace $(<0.0001 \%)$ \\
\hline $\mathrm{C}_{6} \mathrm{~F}_{8}$ isomer, (C6 perfluorocarbon w/ three rings or double bonds) & 224 & ultra-trace $(<0.0001 \%)$ \\
\hline $\mathrm{C}_{6} \mathrm{~F}_{8}$ isomer, (C6 perfluorocarbon w/ two rings or double bonds) & 224 & ultra-trace $(<0.0001 \%)$ \\
\hline $\mathrm{C}_{6} \mathrm{~F}_{8}$ isomer, (C6 perfluorocarbon w/ two rings or double bonds) & 224 & ultra-trace $(<0.0001 \%)$ \\
\hline $\mathrm{C}_{10} \mathrm{~F}_{20}$ isomer, (C10 perfluorocarbon w/ one ring or double bond) & 500 & 0.045 \\
\hline $\mathrm{C}_{10} \mathrm{~F}_{18}$ isomer, (C10 perfluorocarbon w/ two rings or double bonds) & 462 & 0.067 \\
\hline $\mathrm{C}_{10} \mathrm{~F}_{18}$ isomer, (C10 perfluorocarbon w/ two rings or double bonds) & 462 & 0.185 \\
\hline perfluorocarbon monohydride possibly perfluorodecyl-1-hydride & 520 & 0.104 \\
\hline \hline
\end{tabular}

\begin{tabular}{|c|c|c|}
\hline Table 3 GC-MS/GC-FID Profile of F2 Chemicals Ltd. PFH, Batch No. 0219C \\
\hline \hline Peak Assignment & M.W. & GC Area \% \\
\hline perfluorocyclopentane & 250 & 0.108 \\
\hline n-perfluorohexane & 338 & 99.679 \\
\hline perfluoro-2-methylpentane (perfluoroisohexane) & 338 & 0.190 \\
\hline n-perfluorohexyl-1-hydride & 320 & 0.012 \\
\hline n-perfluorobutyl-1-iodide & 346 & 0.010 \\
\hline
\end{tabular}

\section{Fluid Decomposition Behavior at High Temperatures: Thermal Stressing Studies}

\section{Test Matrix}

The FC-72 and PFH perfluorocarbons listed in Section II above were exposed to thermal stress conditions designed to simulate a potential breach of the volatile fluids into the atmosphere aboard the International Space Station (ISS) and subsequent exposure of the vapors to high temperature and catalyst associated with the Trace 
Contaminant Control Subsassembly (TCCS) used for air purification. The TCCS operates at $450^{\circ} \mathrm{C}$ in the presence of a palladium-coated alumina catalyst. This temperature is higher than the $200^{\circ} \mathrm{C}$ listed on the MSDS for potential thermal breakdown. One potential by-product listed is perfluoroisobutene (PFiB). PFiB's are extremely toxic with a low threshold.

Thermal stressing tests were performed in the $200-450{ }^{\circ} \mathrm{C}$ range in the vapor phase diluted in air or inert atmosphere (nitrogen) with and without catalyst exposure. The transit time through the thermal reaction zone was modeled on the residence time of atmospheric gases passing through the heated catalyst in the TCCS and the experiments were conducted at or near atmospheric pressure. It was desired to study the pyrolysis effect and interaction of the TCCS catalyst material and air on these fluids. The test matrix is summarized in Table 4.

\begin{tabular}{|c|c|c|}
\hline & \multicolumn{2}{c|}{ Table 4 Pyrolysis Testing Matrix for FC-72 and PFH Fluids } \\
\hline \hline Variable & Samples & Pyrolysis Condition \\
\hline A & FC-72 \& Aldrich PFH & $200{ }^{\circ} \mathrm{C}$ in Air, No TCCS Catalyst \\
\hline B & FC-72 \& Aldrich PFH & $30{ }^{\circ} \mathrm{C}$ in Air, No TCCS Catalyst \\
\hline C & FC-72 \& Aldrich PFH & $450{ }^{\circ} \mathrm{C}$ in Inert Atmosphere (Nitrogen), \\
& No TCCS Catalyst \\
\hline D & FC-72 \& Aldrich PFH & $450{ }^{\circ} \mathrm{C}$ in Air, No TCCS Catalyst \\
\hline E & $\begin{array}{c}\text { FC-72 \& Aldrich PFH }+ \\
\end{array}$ & $450{ }^{\circ} \mathrm{C}$ in Air,W/ TCCS Catalyst \\
\hline
\end{tabular}

\section{$\underline{\text { Pyrolysis Apparatus }}$}

A pyrolysis system was designed and constructed specifically for these tests. The system was designed to accurately and precisely provide the required pyrolysis temperature in air and/or inert atmosphere (nitrogen). Also, it provided a controlled dwell time at the required temperature in the presence or absence of TCCS catalyst material as required. Pyrolysis experiments were conducted under dynamic conditions in the vapor phase in a flow of carrier gas (air or nitrogen) so that samples remained near or only slightly above atmospheric pressures during high temperature and/or catalyst exposure. This better simulates a potential leak scenario in the ISS if FC-72/PFH vapors were to enter the atmosphere and pass through the TCCS module.

The pyrolysis apparatus is shown in Figure 2. On the right hand side of the apparatus carrier gas is delivered into an injection port on the inlet side of the system via $1 / 8$ " o.d. PTFE tubing and a SS quick-connect fitting. Ultra high purity air or nitrogen serve as carrier gas and the flow rate is controlled by two-stage regulators at the source tanks 
followed by a SS needle valve for fine control. The flow rate through the system was calibrated and adjusted to 100 $\mathrm{ml} / \mathrm{min}$. measured at the outlet exhaust using a NIST-traceable digital flowmeter. The injection port consists of a SS injection body equipped with a Teflon-faced, high temperature stable, silicone rubber septum (Supelco Thermogreen LB-2). The injector is connected to the pyrolysis chamber by a $25 \mathrm{~cm}$ length of $1 / 4$ " o.d. glass lined SS tubing (GLT) that acts as a thermal insulator to prevent the injector and carrier gas inlet from overheating.

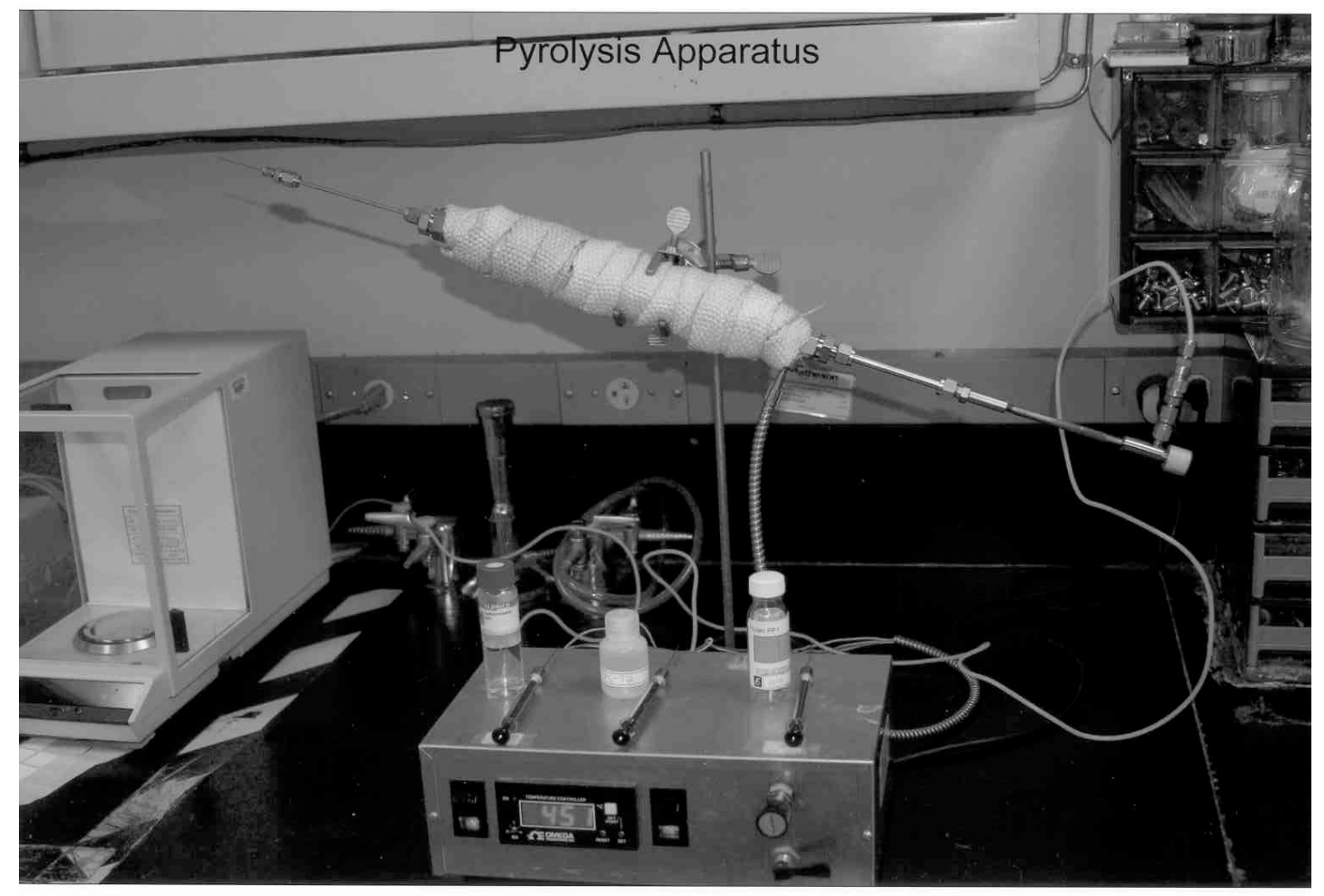

Fig. 2 Apparatus for pyrolysis testing of PFH/FC-72 samples.

The pyrolysis chamber consists of a $30 \mathrm{~cm}$ length of type $316 \mathrm{SS}$ tubing with a $1 \mathrm{~cm}$ i.d.. The tube is connected to the inlet and outlet ports using SS Swagelock reducing unions. The pyrolysis experiments are run with the tube empty (no TCCS catalyst exposure) or packed with TCCS catalyst material. When packed with catalyst, the column contained 15.0 grams of pellets ( $0.5 \%$ palladium on alumina, Engelhard Lot 3550$)$ held in place by two plugs of pre-conditioned fused silica wool (pre-cleaned by solvent extraction and high temperature bakeout). The pyrolysis tube is heated with a high-wattage, coiled 1/8" diameter $120 \mathrm{VAC}$ cable heater. Feedback control for the digital temperature controller was provided by a SS sheathed J-type thermocouple (Watlow) inserted into the middle 
of the thermal reaction tube and held in place by a welded $1 / 16$ " Swagelock tube fitting. The heating tube is wrapped with several layers of glass fiber tape for thermal insulation.

Heating control was maintained with a precision of $\pm 1.0{ }^{\circ} \mathrm{C}$ using a digital temperature controller (Omega) with thermocouple feedback control. Temperature control was calibrated to internal tube temperature with normal flow of carrier gas. The controller can be viewed at the bottom-center of Figure 2. The outlet of the pyrolysis apparatus consists of a $15 \mathrm{~cm}$ long 1/8" o.d. GLT transfer line terminating in a side-port SS needle adapter. SS Swagelock unions are used for connections to the pyrolysis tube and needle.

Please note that the entire pyrolysis apparatus is constructed entirely of inert materials such as type 316 SS, GLT tubing and Teflon. All ferrules and fittings in the high temperature zones were SS. No elastomeric o-rings or rubber seals were used as these can out-gas contaminants when heated.

\section{Pyrolysis of FC-72/PFH Samples}

Prior to conducting pyrolysis experiments on the fluorocarbons, the carrier gas flow was initiated and calibrated and the desired temperature was set on the pyrolysis tube. The system was then allowed to equilibrate and bake-out for approximately 60 minutes to vent off any trace contaminants potentially out-gassing from the construction materials or catalyst. A 1.0 liter Tedlar gas sampling bag was then connected to the needle adapter outlet and a method blank was collected and analyzed to verify a clean system. Finally, pyrolysis experiments were then conducted on the perfluorocarbon samples.

In a pyrolysis experiment, a 1.0 liter Tedlar gas sampling bag was connected to the needle adapter of the preconditioned system by piercing through a septum on the bag. As carrier gas is flowing through the system at a rate of $100 \mathrm{ml} / \mathrm{min}$, the bag inflates. For the actual pyrolysis experiment, $1.0 \mathrm{ml}$ of the fluorocarbon liquid was then injected into the apparatus with the use of a gas-tight syringe at the rate of approximately $1.0 \mathrm{ml}$ per minute. The fluorocarbon liquids vaporize in the injector and the vapors are swiftly moved through the pyrolysis tube by the carrier gas and the pyrolysis products are collected into the Tedlar bag. Sample collection was allowed to proceed for approximately 10 minutes until the Tedlar bags were filled to capacity. Bags were then removed and stored for a short period prior to chemical analysis by GC-MS and GC-FID.

Dwell time of fluorocarbon vapor in the pyrolysis zone was estimated based on linear carrier velocity of the purge gas and dead-volume inside the apparatus. Dead-volume of the system was measured after the pyrolysis 
experiments by filling up the apparatus with water and measuring its volume. The empty system without the TCCS catalyst packing had a dead volume of $27.5 \mathrm{ml}$, while the system with the TCCS catalyst had a dead-volume of 18.5 ml. Assuming a constant carrier gas flow rate of $100 \mathrm{ml} / \mathrm{min}$. and no back-diffusion of vapor into the system from the Tedlar bag, the minimum dwell time for samples in the thermal zone were calculated to be approximately 17 seconds for the empty system and 11 seconds for the TCCS catalyst -ontaining system. If back diffusion of sample from the Tedlar bag occurred during the pyrolysis experiments the maximum possible dwell time for any fluorocarbon contact with the thermal zone would be 10 minutes which was the duration of the entire experiment. However, this latter scenario is unlikely since the needle gauge on the outlet of the apparatus is narrow and the sample and carrier gas exit the system under slight positive pressure which would be expected to prevent any significant level of back-streaming. The dwell time of atmospheric gases passing through the TCCS on the ISS is reportedly less than 2 seconds. ${ }^{21}$

\section{Analysis of FC-72/PFH Samples}

Following collection of perfluorocarbon samples after pyrolysis under the specified conditions, the samples were subjected to complete chemical analysis by GC-MS and by GC-FID and a mass balance was performed. The samples were carefully checked for changes in chemical composition by comparing the pyrolysis data to the analysis results performed previously on the neat liquids before exposure. For the mass balance, $1.0 \mathrm{ml}$ of each perfluorocarbon fluid was injected into a $1.0 \mathrm{~L}$ Tedlar bag, evaporated into the gas phase and diluted to volume with nitrogen. Tedlar bags prepared in this manner, and samples collected after pyrolysis were analyzed by GC-FID. The total area under the curve (AUC) of the GC-FID chromatograms before and after pyrolysis were used to calculate mass balance for the experiments.

The PFH and FC-72 pyrolysis samples were analyzed in the gas phase directly sampled from the Tedlar bags by capillary GC-MS using both EI and NICI modes of operation. The samples were also analyzed by GC-FID. The GC-FID analyses were conducted to provide quantitative data on sample purity (GC Area \%) and for mass balance following the pyrolysis exposure. The GC-MS and GC-FID analysis conditions were identical to those already described in Section II for the structure and impurity profiling of the neat liquids with only slight modification for sample injection technique. The pyrolysis gases were analyzed by injecting $0.1-0.25 \mathrm{ml}$ aliquots of vapor from the 
Tedlar gas sampling bags using a pre-heated, $1.0 \mathrm{ml}$ volume gastight syringe equipped with an on/off valve (Dynatech Pressure-Lok ${ }^{\mathrm{TM}}$ ).

\section{$\underline{\text { Perfluoroisobutylene (PFiB) Specific Analysis }}$}

Due to the known high toxicity of PFiB, specific ultra-high sensitivity analyses were performed for this compound to check if it is produced as a pyrolysis product of any of the perfluorocarbon liquids. A certified analytical reference sample of PFiB was purchased at a concentration of 33.17 parts per million (PPM) v/v in nitrogen from Scott Specialty Gases (Plumsteadville, Pa). A gas-phase serial dilution of this sample was prepared in nitrogen to prepare a working standard at a final concentration of 33.17 parts per billion (PPB) v/v. The 33.17 PPB reference standard of PFiB was used to validate the detection limit of this compound using GC-MS in NICI mode using the exact same conditions as for pyrolysis study samples.

\section{Results \& Discussion for PFH/FC-72 Thermal Stressing Studies}

The results of the pyrolysis study are summarized in Table 5. None of the perfluorocarbon study samples were significantly degraded by any of the pyrolysis conditions. Mass balance before and after pyrolysis confirmed this result quantitative. Table 5 lists the percentage of PFH in the initial liquid samples and following pyrolysis under the various study conditions. Please note that for FC-72, the percentages listed are the sum of branched plus linear $\mathrm{C}_{6} \mathrm{~F}_{14}$ isomers. As far as the major components of all samples are concerned, essentially no decomposition was noted under any of the pyrolysis conditions. Some decomposition of trace level impurities associated with the Aldrich and F2 Chemicals PFH samples was noted. These samples contain trace impurities of compounds such as linear perfluorocarbon monohydrides and monoiodides and some unsaturated or cyclic-unsaturated perfluorocarbons. The more aggressive pyrolysis conditions were found to degrade these impurities so they were no longer present in the samples following pyrolysis at the upper limit. As a consequence, the purity of PFH in these instances actually increased slightly as the pyrolysis procedure effectively scrubbed the samples of these impurities. This effect can be observed as slight increases in PFH percentages in Table 5 with increasing pyrolysis temperature. Since the impacted impurities were trace level to begin with the overall effect is trivial. Presumably, these hydrogen and iodine-containing trace-level impurities were decomposed into non-volatile radical species. Also, at the highest temperature condition of pyrolysis, some trace level $(<0.001 \%)$ of oxygenated-perfluorocarbon decomposition 
products were noted in the Aldrich and F2 Chemicals PFH samples. Some of the unsaturated or cyclic-unsaturated trace level impurities in the Aldrich sample (224 M.W. $\mathrm{C}_{6} \mathrm{~F}_{8}$ isomers \& 262 M.W. $\mathrm{C}_{6} \mathrm{~F}_{10}$ isomer) disappeared following pyrolysis and several trace-level oxygenated-perfluorocarbon pyrolysis products appeared. Presumably, these compounds are oxidation products of the unsaturated or cyclic-unsaturated impurities originally present in the virgin Aldrich PFH liquid.

No trace of PFIB was detected in any of the test samples. This compound was specifically monitored in all samples by GC-MS in NICI mode. The limit of detection for this compound was validated using an analytical reference standard to be at least $33.17 \mathrm{PPB}$ concentration. However, the strong signal to noise $(\mathrm{s} / \mathrm{n})$ ratio $(2.33 \mathrm{x}$ $10^{3}$ ) of the PFiB peak in the NICI-GC-MS data indicates the estimated lower limit of detection is at least 10 PPB.

\begin{tabular}{|c|c|c|c|c|c|c|}
\hline \multicolumn{7}{|c|}{ Table 5: Results Summary of Pyrolysis Study (Dwell Time 11-17 Seconds in Thermal Zone) } \\
\hline \multirow[b]{2}{*}{ Sample ID } & \multirow[b]{2}{*}{$\begin{array}{c}\text { Initial } \\
\text { Purity } \\
\%\end{array}$} & \multicolumn{5}{|c|}{ \%Purity of n-PFH or PFH Isomers Following Pyrolysis at: } \\
\hline & & $\begin{array}{c}200^{\circ} \mathrm{C} \text { in } \mathrm{Air} \\
\text { (No TCCS } \\
\text { Catalyst) }\end{array}$ & $\begin{array}{c}3^{30} \mathrm{C} \text { in Air } \\
\text { (No TCCS } \\
\text { Catalyst) }\end{array}$ & $\begin{array}{l}450^{\circ} \mathrm{C} \text { in } \mathrm{N}_{2} \\
\text { (No TCCS } \\
\text { Catalyst) }\end{array}$ & $\begin{array}{c}450^{\circ} \mathrm{C} \text { in Air } \\
\text { (No TCCS } \\
\text { Catalyst) }\end{array}$ & $\begin{array}{l}4^{450^{\circ}} \mathrm{C} \text { in Air } \\
\text { (W/ TCCS } \\
\text { Catalyst) }\end{array}$ \\
\hline FC-72 & 98.8 & 98.9 & 98.8 & 98.8 & 98.8 & 98.8 \\
\hline Aldrich PFH & 99.4 & 99.4 & 99.6 & 99.5 & 99.4 & 99.8 \\
\hline $\begin{array}{c}\text { F2 Chemicals } \\
\text { PFH (replicate 1) }\end{array}$ & 99.7 & $\mathrm{~N} / \mathrm{A}$ & $\mathrm{N} / \mathrm{A}$ & $\mathrm{N} / \mathrm{A}$ & $\mathrm{N} / \mathrm{A}$ & 99.9 \\
\hline $\begin{array}{c}\text { F2 Chemicals } \\
\text { PFH (replicate 2) }\end{array}$ & 99.7 & N/A & $\mathrm{N} / \mathrm{A}$ & $\mathrm{N} / \mathrm{A}$ & $\mathrm{N} / \mathrm{A}$ & 99.9 \\
\hline
\end{tabular}

\section{Conclusions}

Fluid purity studies showed FC-72 to be only $73.2 \%$ pure n-perfluorohexane. The PFH fluids from Aldrich and F2 Chemicals Ltd were shown to contain $99.4 \%$ and $99.7 \%$ n-perfluorohexane respectively. In addition to the safety aspects, the purer fluid also yields better science results due to the pure fluid having only one discreet boiling point. Isomers of perfluorohexane have slightly different boiling points.

The FC-72 and PFH samples from Aldrich and F2 Chemicals Ltd showed no significant degradation following pyrolysis even under the most aggressive study conditions of $450{ }^{\circ} \mathrm{C}$ in air in the presence of TCCS catalyst material. Some trace level impurities associated with the Aldrich and/or F2 Chemicals PFH samples such as linear perfluorocarbon monohydrides or monoiodides were destroyed by pyrolysis at the upper limit and the purity of PFH 
following pyrolysis actually increased slightly as a consequence. The virgin Aldrich PFH sample contains some trace level unsaturated or cyclic-unsaturated perfluorocarbon impurities that presumably oxidized during pyrolysis at the upper limit forming some trace level $(<0.001 \%)$ oxygenated-perfluorocarbon decomposition products. For example, it is postulated that compounds such as perfluorocyclohexene are oxidized into compounds such as perfluorocyclohexanone.

No trace of PFiB was observed in any of the perfluorocarbon samples before or after pyrolysis. The detection limit of the analytical method for PFiB was validated at $33.17 \mathrm{PPB} v / \mathrm{v}$ but was estimated to be at least $10 \mathrm{PPB}$ v/v based on the strong observed s/n ratio (2.33e 3$)$ in the NICI-GC-MS data.

Testing and analyses are also underway regarding two other $3 \mathrm{M}$ fluorocarbon engineering fluids, HFE-7000 (methyl perfluoropropyl ether) and HFE-7500 (2-trifluoromethyl-3-ethoxydodecafluorohexane).

Fluorocarbon fluids hold great promise in future space-based heat transfer applications. These fluids could potentially reduce size and weight of heat transfer apparatuses while vastly improving performance. The work presented here and the work being performed on other fluorocarbon fluids is not only applicable for the specific space experiments for which they were originally intended, but rather also represents a stepping stone in getting these and other fluorocarbon fluids approved for general heat transfer applications in future space missions.

\section{Acknowledgements}

This research was supported by the Human System Research and Technology Development (HSR\&T) Program at NASA Headquarters. 


\section{References}

1 Samonski, F. H. Jr., and Tucker, E. M., “Apollo Experience Report - Command and Service Module Environmental Control System,” NASA TN D6718, 1972.

2 Nason, J. R.; Wierum, F. A.; Yanosy, J. L., “Challenges In The Development Of The Orbiter Active Thermal Control Subsystem,” NASA. Johnson Space Center Space Shuttle Tech. Conf., Pt. 1/ p 450-464, 1985.

3 Tatara, J. D., Perry J. L and Franks G. D., "Overview of the International Space Station System Level Trace Contaminant Injection Test,” NASA/TM-1997-208137; International Conference on Environmental Systems (ICES), Danvers, MA, 13-16 Jul. 1998 , 19970101; 1997

4 3M, Material Safety Data Sheet on FC-72 3M Performance Fluid. 3M, St. Paul, MN, 1995

5 Riess JG, "Blood substitutes and other potential biomedical applications of fluorinated colloids, "Journal Of Fluorine Chemistry Vol 114, pp 119-126, 2002

6 Waritz, R. S. and Kwon, B. K., "The Inhalation Toxicity of Pyrolysis Products of Polytetrafluoroethylene Heated Below 500 Degrees Centrigrade," American Industrial Hygiene Association Journal, p 19- 26, 1968, 7 Kennedy, G. L. Jr., and Geisen, R. J., "Setting Occupational Exposure Limits for Perfluoroisobutylene, A Highly Toxic Chemical Following Acute Exposure,” Journal of Occupational Medicine, Vol. 27, No. 9, p 675, 1985.

8 Lehnert, B. E., Archuleta, D., Behr, M. J., and Stavert, D. M., "Lung Injury after Acute Inhalation of Perfluoroisobutylene: Exposure Concentration - Response Relationships, "Inhalation Toxicology, Vol. 5, 1-32, 1993.

9 Warheit, D. B., Seidel, W. C., Carakostas, M. C., and Hartsky, M. A, “Attenuation of Perfluoropolymer Fume Pulmonary Toxicity: Effect of Filters, Combustion Method, and Aerosol Age," Experimental and Molecular Pathology, Vol 52, 309-329, 1990.

10 Lee, K. P., and Seidel. W. C., "Pulmonary Response of Rats Exposed to Polytetrafluoroethylene and Tetrafluoroethylene Hexafluoropropylene Copolymer Fume and Isolated Particles," Inhalation Toxicology, Vol. 3, 237-264, 1991. 
11 Oberdorster, G., Gelein, R. M., Ferin, J., and Weiss, B., "Association of Particulate Air Pollution and Acute Mortality: Involvement of Ultrafine Particles?” Inhalation Toxicology, Vol. 7, 111-124, 1995.

12 Hauptschein, M. Fainberg, A. H., and Braid, M. "The Thermal Dimerization of Perfluoropropene,” Journal of the American Chemical Society, Vol. 80, 842-845, 1958.

13 Salmon, R. P. DiFelice, J. J., and Ritter, E. R., “An Experimental Study of the Formation of Perfluoroisobutene," Combustion Science and Technology, Vol. 134, 65-85, 1998.

14 Tortelli V., Tonelli, C., and Corvaja, C., "Thermal Decomposition Of Branched-Chain Perfluroalkanes,” J. Fluorine Chemistry 60: 165-174, 1993.

15 Tonelli, C. and Tortelli V., "Pyrolysis Of Branched-Chain Perfluoroalkanes In The Presence Of Halogens". J. Fluorine Chemistry 67: 125-128, 1994.

16 Ainagos, A.F. “Mechanism And Kinetics Of Pyrolysis Of Perfluorohexane,” Kinetics And Catalysis, Vol. 32 pp. 720-725, 1991.

17 Arito H. and Soda, R, "Pyrolysis Products of Polytetrafluoroethylene and Polyfluoroethylenepropylene with Reference to Inhalation Toxicity,” Annals of Occupational Hygiene, Vol. 20, pp. 247-255, 1977.

18 Trowbridge, L. D, "Potential Hazards Relating to the Pyrolysis of c-C4F8 in selected Gaseous Diffusion Plant Operations, ORNL/TM-13758, 1999.

19 Trowbridge, L. D, "Potential Hazards Relating to the Pyrolysis of c-C4F8O, n-C4F10 and c-C4F8 in selected Gaseous Diffusion Plant Operations, ORNL/TM-2000/68, 2000.

20 DeCorpo , J. J, Holtzclaw, J. R., and Clark, R. C., “Testing and Evaluation of Potential Hazards from a Teflon Impregnated Packing,” NRL Memorandum Report 4026, 1979.

21 Perry, J. L, “Space Station Freedom Environmental Control and Life Support System (ECLSS) Phase III Simplified Integrated Test Trace Contaminant Control Subsystem Performance, “ NASA TM 4202, 1990. 